\title{
La gráfica como artefacto cultural. Una aproximación semiótica al cartel social en Chile.
}

\section{Graphic as a cultural Artifact. A semiotic approach to social poster in Chile}

\author{
ENRIQUe VERGARA-LEYTON \\ enrique.vergara@udp.cl \\ Universidad Diego Portales. Chile \\ Claudio Garrido-Peña \\ claudio.garridop@udp.cl \\ Universidad Diego Portales. Chile \\ Camila Undurraga-Puelma \\ camilaup@gmail.com \\ Universidad Diego Portales. Chile
}

Recibido: 12 de marzo de 2013

Aprobado: 26 de junio de 2013

\section{Resumen}

Este artículo presenta una revisión crítica de la semiótica al estudio de la imagen, con el objetivo de formular una propuesta de análisis aplicada al cartel en Chile. Con esto, se busca contribuir a los estudios de la imagen, incorporando enfoques que complementen las perspectivas clásicas de análisis. El método utilizado mantiene el uso de categorías de la semiótica e incorpora los contextos de producción y decodificación de los mensajes, al analizarlos como parte de un contexto simbólico mayor. La muestra analizada estuvo compuesta por carteles que abordaron temáticas sociales entre los años 1970 y 1973, correspondientes al gobierno de Salvador Allende, y que tuvieron un gran impacto en el espacio público local. Los resultados dan cuenta de una propuesta estética y comunicacional, que expresó la voluntad de construir un nuevo tipo de sociedad, y su forma de ser representada, a través de actores sociales funcionales al proyecto político en marcha, incorporando referentes visuales tanto del mundo popular como de la cultura de masas. Esta síntesis visual, otorgó al cartel chileno un gran potencial comunicativo, capaz de sintonizar con las demandas de cambio y de validar, a su vez, un relato propio como correlato de un marco ideológico mayor.

Palabras clave: cartel, semiótica, gráfica, estética.

Vergara-Leyton, E., Garrido-Peña, C., Undurraga-Puelma, C. (2014): La gráfica como artefacto cultural. Una aproximación semiótica al cartel social en Chile. Arte, Individuo y Sociedad, 26(2) 271-285.
Abstract
This article presents a critical review of the contribution of semiotics to the study of image, with the aim of formulating a proposal of analysis applied to poster in Chile. It seeks to contribute to the study of image, incorporating new approaches to complement the classical perspectives of analysis. The 
method used keeps using semiotics categories and includes the contexts of production and decoding of messages, when analyzing them as part of a bigger symbolic context. The sample analyzed was composed of posters that addressed social issues developed between 1970 and 1973, for the government of Salvador Allende,that had a huge impact in the local public space. The results of the analysis shows an aesthetic and communicational proposal that expressed the desire to build a new kind of society and its way of being represented through functional stakeholders to the political and social project at the time and incorporating visual references from the popular world and the mass culture. This visual synthesis, gave to the Chilean poster a great communicative potential able to tune with the changing demands of a wide audience, and also to validate its own narrative as part of narrative from a larger ideological framework.

Keywords: poster, semiotics, graph, aesthetics.

Vergara-Leyton, E., Garrido-Peña, C., Undurraga-Puelma, C. (2014): Graphic as a cultural Artifact. A semiotic approach to social poster in Chile. Arte, Individuo y Sociedad, 26(2) 271-285.

Sumario: 1. Introducción, 2. Marco conceptual, 2.1 Aproximaciones al análisis semiótico en el ámbito de la imagen, 2.2. Algunas consideraciones sobre el cartel social en Chile, 3. Metodología, 4. Resultados, 4.1. Análisis categorial, 5. Conclusiones. Referencias.

Este artículo recoge resultados de la investigación Arte, poder y consumo en Chile: la gráfica como artefacto cultural entre 1970 y 1980. Del afiche al aviso de prensa, financiada por el Fondo Nacional de Investigaciones Científicas y Tecnológicas de Chile. FONDECYT. Proyecto Regular 2011-2012 $n^{\circ} 1110616$.

\section{Introducción}

A continuación se presentará una revisión crítica de la perspectiva semiótica, aplicada al análisis de la imagen gráfica, para posteriormente, formular una propuesta para la observación del cartel social en Chile. Este cartel, que asume un protagonismo central en el espacio público entre los años 1970 y 1973, llena una vacío comunicacional en un contexto sociopolítico, marcado por profundas transformaciones que buscaban incorporar a amplios sectores de la sociedad - tradicionalmente excluidos - a los procesos de cambio que experimentaba el país. Como ha señalado Sontag (2001: 246), en el contexto, en que las sociedades se consideran a sí mismas en estado de emergencia, el cartel constituye un instrumento para la promoción de actitudes políticas de manera sucinta, como se puede advertir, por ejemplo, en el caso de los carteles de Mayo del 68 (Aulich, 2007; Wlassikoff, 2008) y de la Transición Española a la democracia (López, 1999).

\section{Marco conceptual}

\subsection{Aproximaciones al análisis semiótico en el ámbito de la imagen.}

Según plantea Sáez (1999), históricamente, el análisis semiótico se ha preocupado de múltiples aspectos y sus esfuerzos se han visto divididos entre quienes han tratado de encontrar esquemas teóricos globalizadores, y quienes han tratado de demostrar su validez con estudios de actos de comunicación. Esto se ha traducido en dos grandes corrientes; por una parte los autores norteamericanos, que se han interesado preferentemente por cuestiones lógicas, y por otra, las escuelas europeas que se han ocupado 
de la dimensión pragmática de la semiótica, entendida esta como el estudio del lenguaje en su relación con los usuarios y las circunstancias de comunicación, que es de donde provienen los principales aportes de la semiótica al análisis del discurso. Para efectos de este artículo, es ésta última corriente la que nos interesa.

En cuanto a la presencia de la semiótica en los estudios de comunicación, para Vilches (2001), aunque ésta habría perdido terreno en comparación con conceptos que tienen su origen en otros campos disciplinarios, en la práctica, se continúa utilizando para establecer categorías teóricas para el análisis de la imagen. Para este mismo autor, esta vigencia se explica porque toda teoría de la imagen, presupone una teoría del significado que aborde los sistemas culturales en las operaciones de representación (Vilches, 1985: 28). Desde esta perspectiva, el análisis semiótico es, ante todo, y siguiendo a Floch (1991: 23), "una relación concreta con el sentido".

Es esta vigencia de las categorías teóricas, la que explica por qué el análisis de la imagen se ha visto enriquecido conceptualmente, por los aportes de la semiótica aplicada a los medios masivos, especialmente en el ámbito de la publicidad, los que, no obstante, han sido muy diversos, tanto en lo que se refiere a sus perspectivas teóricas como a los objetivos planteados. Esto se ha expresado en un panorama extraordinariamente heterogéneo respecto de los modelos y escuelas de análisis. (Capdevilla \& Fernández, 2006).

El análisis semiótico aplicado a la publicidad, ha sido objeto de estudio desde los años sesenta hasta nuestros días. Y de acuerdo con lo señalado por Madrid (2005: 209-249), es posible identificar al menos dos modelos: los precursores y los generativos. En el caso de los modelos precursores, uno de sus principales exponentes es Roland Barthes, quien postula que todo aviso publicitario se compone de tres mensajes: mensaje lingüístico; mensaje visual denotado y mensaje visual connotado. Con esto, se busca dar a la comunicación publicitaria el estatus de objeto de estudio, desde una perspectiva estructural, y privilegiando el análisis de la imagen como componente ideologizado, destacando las relaciones entre denotación y connotación, naturaleza y cultura, a través del método estructuralista. Este modelo de análisis se destaca por ser uno de los primeros modelos estructuralistas en el ámbito de la imagen. En sus últimas reflexiones, Barthes va ampliar y complejizar su punto de vista respecto de la publicidad, al considerar que los avisos ofrecen algo más que la mistificación de los productos, lo que se traduce en una visión más abierta respecto del problema de la connotación (Madrid; 2005: 249).

Siguiendo lo que plantea Madrid, el modelo de análisis propuesto por Barthes, da paso a una nueva sistematización de los estudios realizados, a los cuales Umberto Eco va a contribuir desde una perspectiva que considera a la semiótica, como una teoría general que estudia todos los fenómenos comunicativos. Una característica del análisis de Eco es la incorporación del problema estético en sus estudios. Punto interesante de destacar ya que constituye una primera crítica al estructuralismo desde la semiótica (Madrid, 2005: 217). No obstante esta crítica, sus estudios seguirán abordando la retórica publicitaria y la relación de ésta con la ideología, al igual que las otras corrientes estructuralistas. Uno de los primeros modelos de análisis semiótico de la publicidad, propuesto por Eco, se encuentra en su trabajo "Algunas comprobaciones del mensaje publicitario", en el cual, a través de un modelo estrati- 
ficado, distingue entre dos registros: el verbal y el visual. Su interés se centra en los "segmentos semánticos amplios", esto es, los connotados. El modelo desarrollado por Eco, es parte de una tradición y de una época, donde las nociones de estructura, unidad y códigos, son partes constitutivas de los estudios científicos de significación, con una marcada carga ideológica, (Madrid, 2005).

No obstante esto, es interesante destacar, a partir de sus obras posteriores, el carácter "contractual" que asigna a toda forma comunicativa. Estos es, su idea de "cooperación interpretativa" (Eco; 1993, 2000). A este respecto, Semprini (1995: 87) señala que, para Eco, un discurso no solo supone la prefiguración del perfil de los destinatarios, ya que su sentido y la formación de su significado sería en consecuencia, el resultado de un trabajo en común.

En cuanto a los modelos generativos identificados por Madrid, destaca entre otros, el aporte de Jean Marie Floch, quien a partir de una base estructural, propone el "recorrido generativo greimasiano", al discurso de la publicidad. En efecto, Greimas postulaba que el significado aparecía por generación y por narración. Esto es, el significado como enriquecimiento progresivo, a partir de los valores que la sociedad forma, y que serían reales en la medida en que ascienden a la superficie discursiva, donde son "escenificados" por estructuras narrativas y, posteriormente, por figuras y objetos de nuestro entorno (2005: 193).

Desde los estudios culturales, uno de los aportes más significativos al análisis de la imagen en el campo de la comunicación, lo constituye el estudio de Judith Williamson, quien, en un trabajo publicado por primera vez en 1978, se enfoca en la forma en cómo los avisos asumen significados. Es decir, no en qué significan sino en cómo adquieren significado. Para Wells (1994), a nivel analítico, Williamson se concentra en "cómo funciona la cualidad ubicua de los anuncios para crear estructuras de significado". En este punto, rechaza la idea de un solo lenguaje, puesto que la publicidad no puede reducirse a una "gramática única", ya que sus componentes son variables y no forman parte de un solo lenguaje o discurso social determinado. Para Williamson, la forma de significar de la publicidad, que se apoya en la distinción de Saussure entre el significante - la cosa u objeto - y el significado - conceptos-, busca resaltar la importancia del significante, es decir, la cosa u objeto real en el mundo real con todas sus significaciones asociadas.

Según Wells, una de las principales limitaciones del trabajo de Williamson se da al no considerar al receptor como un sujeto activo, individualizado y contextualizado social y culturalmente. Es decir, al centrar la atención en el texto, no considera los contextos - y sus implicaciones-, tanto en la producción donde las imágenes son codificadas, como en la recepción donde son decodificadas.

Si bien la comunicación gráfica, y en un sentido amplio, las diferentes manifestaciones estético-comunicacionales, se explican como partes de contextos socioculturales mayores, es decir, como partes de una época que las condiciona, y de un relato que las valida y da sentido), esto no significa necesariamente que la gráfica responda a una ideología entendida como una estructura - o superestructura- que condiciona unidireccionalmente a los sujetos. La experiencia en la investigación en el ámbito de la recepción de mensajes, realizada en diferentes contextos socioculturales, da cuenta de un receptor activo, dotado de una alta capacidad para resignificar los contenidos 
y de complejos mecanismos para la apropiación de éstos. Lo que se traduce en la necesidad de considerar, en el análisis de los mensajes, las condiciones de recepción, así como las múltiples posibilidades de interpretación como consecuencia del capital simbólico del receptor. Como se ha expuesto anteriormente, los estudios semióticos tienden a poner el acento en la dimensión ideológica del objeto y no en sus condiciones de instalación y validación social. Estos enfoques no profundizan, necesariamente, en las condiciones de construcción del objeto, sus significados sociales y la apropiación del mismo y el contexto sociocultural en el que se genera.

Desde la perspectiva antropológica desarrollada por Appadurai (1991), se reivindica el objeto, en nuestro caso la gráfica, como un artefacto significante que forma parte de un sistema simbólico más amplio, en que se dinamiza la existencia de un imaginario social, la identificación de códigos, formas de producción y materialidad, temporalidad y elementos específicos de significación y de apropiación diferenciados. Bajo este supuesto, se puede explicar la vigencia de objetos, más allá de su temporalidad, como es el caso del cartel social, que al contener un código de significaciones evoca un contexto determinado. Si bien Appadurai no reflexiona específicamente sobre la gráfica, sí es posible considerarla, desde su perspectiva de análisis, como un artefacto tributario de su contexto cultural determinado.

No obstante lo anterior, y pesar de las críticas a los estudios semióticos, es importante destacar conceptos y categorías de análisis desarrollados por la semiótica, como se señaló al inicio. En este sentido, nos parece de gran interés, pese a las limitaciones expuestas, el trabajo Decodificando anuncios de Williamson. En este se presenta una reflexión desde la pieza gráfica, en cuanto objeto intencionalmente construido y dirigido, a la creación de significado en un marco ideológico, en el cual se construye una relación entre el sujeto y la sociedad. Este análisis contiene elementos que se pueden aplicar al estudio del cartel, al poner en valor las condiciones que intervinieron en la generación de este soporte de comunicación y, en segundo término, abordar los referentes, códigos y signos presentes en su propuesta comunicacional.

\subsection{Algunas consideraciones sobre el cartel social en Chile.}

El cartel social en Chile, como objeto de estudio, debe ser entendido en el contexto de las profundas transformaciones que experimentó este país en la década de los años sesenta y setenta, y que tendrán su máxima expresión durante el gobierno de Salvador Allende (1970-1973). Es decir, como un dispositivo de comunicación social que forma parte de un proyecto social y político que buscaba sentar las bases de un nuevo modelo de desarrollo para Chile.

Por otra parte, es importante considerar que durante este mismo periodo, se va a demandar del Estado un rol más activo en el plano cultural. Desde esta perspectiva, el rol asignado a la cultura, y por ende, a los medios de comunicación, es el de "la producción de identidades políticas y sociales funcionales al proceso revolucionario y a la consolidación de una sociedad socialista" (Catalán, 1988). Por lo tanto, los medios de comunicación se consideran fundamentales para la formación de un hombre y de una cultura nueva. Para esto, se proponía dotar al sujeto y su cultura, de una orientación educativa que lo liberara de su carácter comercial. Como consecuencia de lo anterior, el cartel chileno cobrará un fuerte protagonismo como un soporte de comu- 
nicación de las masas, al servicio de un proyecto político, con un fuerte énfasis en las temáticas sociales, en una sociedad con un desigual acceso a la cultura y en la cual, el espacio público urbano, constituye uno de los principales espacios de comunicación.

\section{Metodología}

De acuerdo con lo anteriormente señalado, esta propuesta de análisis se realiza sobre la base de tres ejes centrales aplicables al cartel. En primer lugar, su consideración como objeto, entendido este, como la producción material de un artefacto orientado a una lógica de producción masiva. El segundo eje de análisis, está dado por su estructura significante, esto es, las condiciones de construcción del objeto, las que no se agotan en su materialidad, sino que proponen una significación determinada por una elección y tratamiento de los referentes, tanto a nivel lingüístico como icónico. Finalmente, el último eje de análisis, es la direccionalidad de la pieza gráfica. Si consideramos que toda pieza está orientada a impactar a una audiencia, podemos concluir que la pieza en sí, contiene una propuesta en términos de su valoración, decodificación y significación por parte de otro. Sin embargo, es importante advertir en este punto, que para efectos de este análisis nos circunscribiremos a la propuesta de significación de la imagen gráfica, sin abordar el impacto real en los receptores de los mensajes, lo que constituiría un estudio de recepción. Estos tres ejes, se traducen a su vez en la identificación de tres categorías de análisis: Códigos estéticos, Mensaje y Aspectos relacionales.

La selección de las piezas a analizar fue intencionada, a partir de un corpus de 100 carteles del periodo, cuyas temáticas eran de índole social. Se seleccionaron cuatro carteles que fueron desarrollados por diseñadores de amplio reconocimiento dentro del medio nacional. Para el análisis de cada una de estas piezas, se diseñó una parrilla que consideró las siguientes categoría y subcategorías: Códigos Estéticos (Descripción Cromática, Presencia de Elementos Simbólicos, Descripción Tipográfica y Composición); Mensaje (Texto Principal, Textos de Apoyo, Personajes/Estereotipos e Identificación de Promesa Básica) y Aspectos Relacionales, entendidos estos como la identificación de los elementos de decodificación claves, comunicados por los carteles. Es decir aquellos en los que descansa la intencionalidad de la propuesta y que ponen en contexto aspectos propios del mensaje y la referencia a imaginarios mayores. (Relación Mensaje-Receptor e Imaginario Referencial).

Es importante advertir que esta muestra, no busca ser representativa del universo de los carteles sociales, sino que profundizar en la significación de los mensajes. De ahí que la validez del análisis sea de tipo externa, en el sentido que los resultados reflejen, efectivamente, fenómenos reales sensibles al contexto, en los cuales, más que medir, se pretende captar la riqueza y complejidad de la propuesta comunicacional (Krippendorff, 1990: 230). 


\section{Resultados}

A continuación y en función de lo expuesto, presentamos un análisis de cuatro carteles representativos de la iconografía del periodo estudiado. El objetivo de este ejercicio es realizar una aproximación deconstructiva a las distintas piezas, a partir de categorías, a fin de exponer la mecánica del análisis y las opciones interpretativas que se desprenden de cada objeto de estudio. Los carteles de la selección fueron realizados por dos despachos ampliamente destacados y reconocidos por su obra y contribución a la comunicación durante el periodo estudiado: los despachos de Vicente Larrea-Luis Albornoz y Waldo González-Mario Quiroz.

A fin de transparentar el procedimiento, y con el objetivo de separar teóricamente el análisis de la interpretación, se realizó el ejercicio de categorización para los distintos carteles seleccionados (véase el anexo I).

\section{Carteles seleccionados}

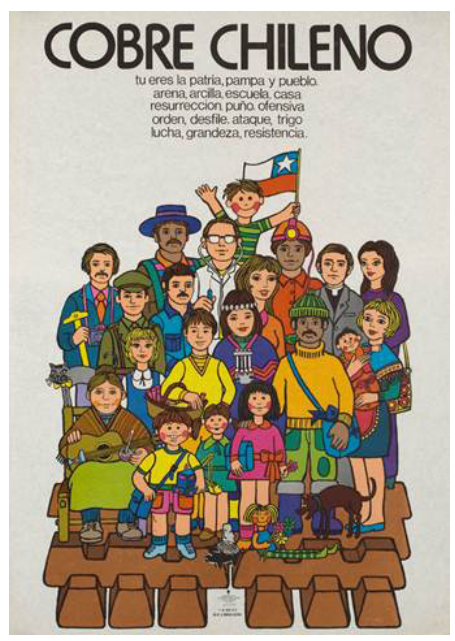

Figura 1. Vicente Larrea-Antonio Larrea-Luis Albornoz Cobre chileno, 1972

Archivo de Originales SLGM. FADEU. Pontificia Universidad Católica de Chile 


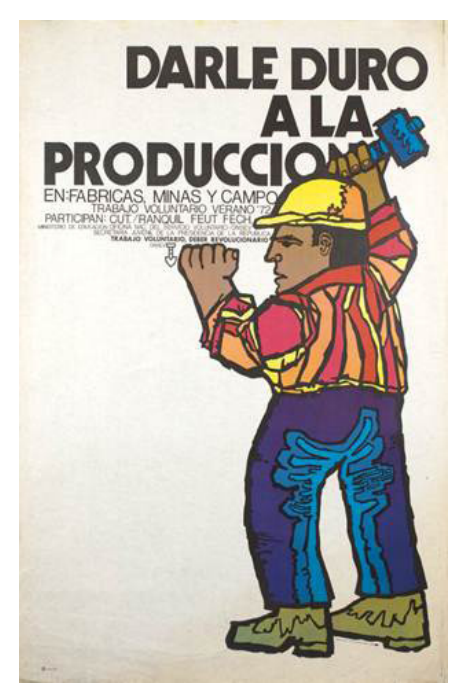

Figura 2. Vicente Larrea-Antonio Larrea-Luis Albornoz Dale duro a la producción, 1972

Archivo de Originales SLGM. FADEU. Pontificia Universidad Católica de Chile

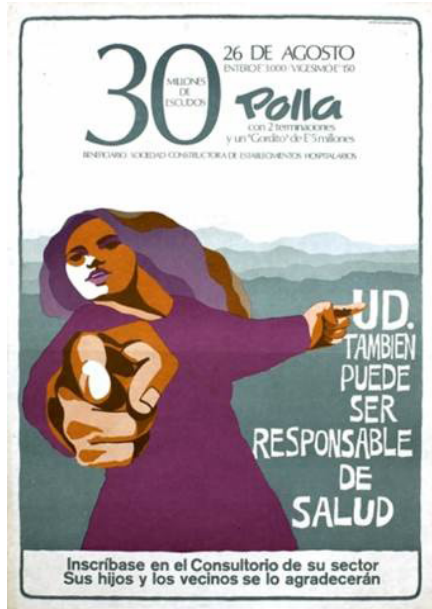

Figura 3. Waldo González-Mario Quiroz

UD. también puede ser responsable de salud, 1973 Colección UTEM. 


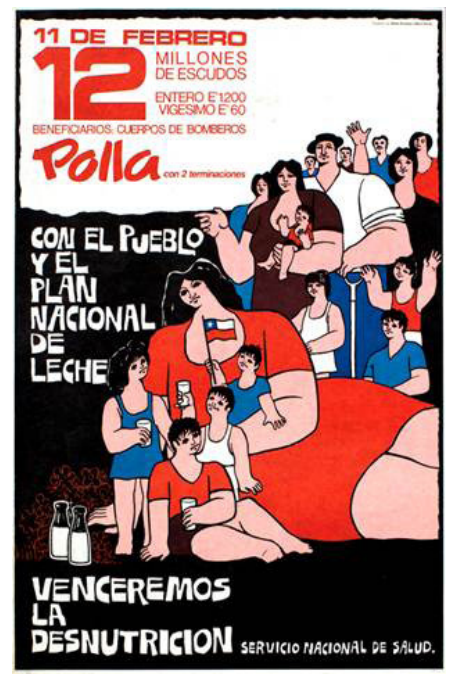

Figura 4. Waldo González-Mario Quiroz

Con el pueblo y el plan nacional de leche venceremos la desnutrición, 1973.

Colección UTEM

\subsection{Análisis categorial}

En primer lugar, se destaca que el conjunto de carteles seleccionados construye un texto gráfico en función de una propuesta conceptual, articulada respecto de la relación entre individuo y sociedad, entendida ésta como la generación de una identidad colectiva - o proyecto sociopolítico- que pone como centro la referencia a lo colectivo, definido esto último como logro deseable: lo bueno para todos y la definición de un actor social protagonista. En función de este concepto, el cartel y sus autores, destinan un conjunto de recursos visuales que pone en valor la referencia de un marco ideológico amplio y la identificación de los actores sociales partícipes de la transformación deseada.

A nivel de códigos estéticos se destaca la amplia presencia y dominio de la ilustración como soporte. Y también, el uso del color como elemento potenciador de la propuesta, en cuanto a su notoriedad y capacidad de representar la diversidad a la cual se hace referencia. Estos elementos confieren a los carteles analizados la capacidad de ser percibidos como dispositivos de propaganda, y a la vez, como objetos artísticos que desarrollan un lenguaje propio. En este entendido, se fortalece la capacidad de 
estos soportes para exponer un valor estético asociado al mensaje que se desea transmitir, sintonizando, de este modo, con el contexto socio-político del periodo: el logro de un proyecto social identitario construido sobre la base de lo popular. El apelativo a lo popular, descansa, no solo en el uso del mensaje escrito literal, sino que se expresa en la presencia gráfica de objetos simbólicos asociados a la cultura popular. O, en un sentido estricto, en el uso de objetos simbólicos evocativos de una experiencia colectiva chilena: bandera, elementos de trabajo, cobre, casco, vaso de leche, etc. La presencia de estos objetos buscó facilitar la capacidad de decodificación de los distintos mensajes, al acercar el contenido ideológico al individuo en su contexto cotidiano.

De manera evidente, los carteles analizados dan una preeminencia a la imagen por sobre el texto. La imagen es protagonista dada su capacidad de convocar, a través de la representación, a los actores sociales: pueblo viendo al pueblo, pueblo interpelado por la imagen idealizada del pueblo. Este punto es de vital importancia en el análisis de la gráfica del periodo, dado que se asiste a la configuración de un relato que se constituye respecto de una imagen de ficción de lo popular, que desplaza la tradicional imagen folklórica. Se utilizan códigos estéticos del pueblo urbano-masivo y popular, traspasados por la necesidad de construir un relato identitario propio. En un sentido amplio: es la búsqueda de un imaginario visual popular de la modernidad, lo que se ve potenciado por el uso de influencias estéticas que descansan en la necesidad de generar mensajes propios de la experiencia moderna colectiva, como el Pop Art, en el caso de las piezas de Vicente Larrea-Luís Albornoz. O, en la necesidad de crear referentes de la identidad y el sujeto latinoamericano, como el caso del imaginario popular en la obra de Waldo González-Mario Quiroz.

A nivel de mensajes, se destaca la sintonía que se observa entre los aspectos estéticos y la propuesta comunicacional de los distintos carteles analizados. Esta sinergia de elementos confiere, a las distintas piezas, la cualidad de actuar como relatos autónomos conectados por un concepto mayor: el proyecto social y el papel del individuo. De este modo podemos advertir la existencia de dos ejes de construcción del mensaje, el primero de ellos, desde una lógica testimonial, presente en las obras de Vicente Larrea-Luís Albornoz (Fig. 1, Cobre Chileno y Fig. 2 Darle Duro a la Producción) con contenidos de mayor abstracción, tributarios del proyecto político del gobierno de la Unidad Popular, a través de la nacionalización del cobre y del fortalecimiento de la plataforma productiva nacional, las cuales funcionan como declaraciones temáticas formales, utilizando la referencia a tipografías y a textos de apoyo poéticos en el cartel Cobre Chileno (Fig. 1) o, a organizaciones sociales formales de trabajadores en el caso de Darle Duro a la Producción (Fig. 2). Un segundo eje se advierte en las piezas de Waldo González-Mario Quiroz Venceremos la desnutrición (Fig. 4) y Ud. también puede ser responsable de Salud, (Fig. 3) en las cuales el mensaje se estructura en torno a la idea de la identidad colectiva "pueblo" y en el papel del individuo en la mejora de los problemas sociales que impactan de manera directa en la calidad de vida de estos segmentos. Ambas piezas se estructuran en torno al apelativo de lo colectivo y a la responsabilidad del individuo, identificando mecánicas de acción específicas, asociadas a la concreción del involucramiento efectivo de la audiencia. En este contexto, se perfila como de especial importancia, la presencia de distintos estereotipos en los carteles analizados, los que cumplen la función de testimoniar, 
tanto lo colectivo popular como la interpelación a la acción individual en cuanto a motor de cambio.

De acuerdo a los aspectos relacionales que se desprenden de este análisis, y conforme con lo anteriormente expuesto, las distintas piezas proponen como texto de apropiación central, la apelación a la identidad colectiva y la existencia de sujetos sociales de mayor dominio y trascendencia, que el interés particular del individuo, que es interpelado en su papel y responsabilidad histórica. Si bien este es el texto amplio en el que reside la propuesta de los distintos carteles, se destaca la identificación de un sujeto colectivo ampliamente heterogéneo. La comunicación de la idea de un pueblo, está constituida sobre la base de hacer del rol, posición y disposición del individuo; aspectos que se rescatan tanto en la disposición de recursos iconográficos como en el texto presente en las distintas piezas gráficas. Lo anterior adquiere expresión propia en cada uno de los carteles. Por ejemplo en el caso de Cobre Chileno (Fig. 1), se observa la apelación directa a un pueblo diverso, más allá de la estratificación social sustentado por el cobre como riqueza común de todos los chilenos. Esta propuesta adquiere una dinámica de acción social, en el caso del cartel Venceremos la desnutrición (Fig. 4), en el cual el pueblo en su diversidad, define un objetivo común a través de la mecánica simple de beber leche. A su vez, en las piezas Darle duro a la producción (Fig. 2) y Ud. puede ser responsable de salud (Fig. 3), observamos un llamado al involucramiento individual respecto del papel transformador, ya sea desde sus capacidades productivas como desde su responsabilidad comunitaria.

\section{Conclusiones}

La contribución del análisis realizado descansa, a nuestro juicio, en primer lugar, en la estructuración de un marco categorial que integra las condiciones de producción y lenguaje propias del cartel social, estimulando un análisis que trabaja de manera complementaria tanto los aspectos estéticos de la construcción de la pieza como su apelación a un contexto de comunicación de mayor amplitud. Lo anterior permite separar, operativamente, la identificación de los aspectos figurativos que construyen el relato de la pieza, de su interpretación como obra total. Si bien este paso solo puede sostenerse dentro de una lógica analítica, se posibilita la puesta en valor de los aspectos simbólicos y estéticos; la propuesta de mensaje y el conjunto de decisiones de autor que otorgan al cartel la dimensión de artefacto cultural en el Chile de los años setenta. Lo anterior nos remite a un aspecto de gran importancia en el desarrollo del análisis de la imagen: la necesidad de establecer comparaciones que permitan identificar las propuestas de significación de distintos objetos, en contextos culturales diferenciados. A este respecto, cabe hacer notar que el análisis de estos carteles no desecha su dimensión ideológica, sino que la utiliza como elemento generador de un marco de sentido general, en el que se inserta la comunicación gráfica.

Es esta aproximación al análisis de la imagen, la que nos permite determinar que, a través del cartel social chileno de este periodo, se promovió una visualidad asociada a un proyecto político, en sintonía con el mundo popular y a la vez, con la cultura de masas. Lo que al mismo tiempo, expresó la voluntad de construir un nuevo tipo de sociedad y sus formas de representarla, en lo cual, el protagonismo está dado por los 
actores sociales de las trasformaciones que experimentaba Chile. Esto respondió a la necesidad de validar a estos actores, en función del tipo de sociedad que se buscaba construir. Es decir, un relato estético-comunicacional propio, como correlato de un marco ideológico mayor que lo validó y dio sentido.

En esta búsqueda por construir una identidad propia, el cartel social va a recurrir a expresiones estéticas de variada índole. Esta dimensión ecléctica, que da cuenta de una amplia diversidad de referentes, otorgó al cartel una gran potencia comunicativa, capaz de sintonizar con las demandas de una audiencia heterogénea que se enfrentaba a una multiplicidad de referentes visuales, característicos de un contexto democrático, como era el caso de Chile al inicio de la década de los años setenta.

\section{Referencias}

Appadurai, A. (1991). La vida social de las cosas. México: Grijalbo Consejo Nacional para la Cultura y las Artes, 1991.

Aulich, J. (2007). War posters. Weapons of mass communication. Nueva York: Thames \& Hudson.

Capdevila, A. \& Fernández, J. (2006). "Aplicación de un modelo retórico al análisis de la publicidad televisiva". En III Simposium de Profesores Universitarios de Creatividad Publicitaria. Barcelona: Ediciones Trìpodos URL.

Eco, U. (2000). Los límites de la interpretación. Barcelona: Lumen, 2000.

- (1993). El lector in fabula. La cooperación interpretativa en el texto narrativo. Barcelona: Lumen, 1993.

Floch, J. M. (1991). Semiótica, marketing y comunicación: bajo los signos, las estrategias. Barcelona: Ediciones Paidós.

Krippendorff, K. (1990). Metodología de análisis de contenido. Teoría y práctica. Barcelona: Paidós Ediciones.

López, P.A. (1999). Carteles en libertad: ¿cómo se llega al pueblo con un cartel? Comunicar, 13, 148-151.

McQuail, D. (1991). Introducción a la teoría de la comunicación de masas. Barcelona: Ediciones Paidós.

Madrid, S. (2005). Semiótica del discurso publicitario. Del signo a la imagen. Murcia: Publicaciones de la Universidad de Murcia, 2005.

Sáez, A. (1999). De la representació a la realitat. Barcelona: Deria Editors.

Semprini, A. El marketing de la marca. Una aproximación semiótica. Barcelona: Paidós, 1995.

Sontag, S. (2001). "El afiche: publicidad, arte instrumento político, mercancía". En M. Bierut, J. Helfand, S. Heller \& al. (Eds.), Fundamentos del diseño gráfico (pp. 239-265). Buenos Aires: Ediciones Infinito.

Vilches, L. (2001). "Tecnologías digitales al servicio de los archivos de imágenes". En revista Anàlisi. Quadern de Comunicación i Cultura $\mathrm{N}^{\circ} 27$. Barcelona: Servicio de Publicaciones UAB.

-(1995). La lectura de la imagen. Barcelona: Ediciones Paidós. 
Welle, L. (1994). "Judith Williamson, Decodificando anuncios". En M. Barker/A. Beezer (Eds.), Introducción a los Estudios Culturales. Barcelona: Bosch.

Williamson, J. (1978). Decoding Advertisements: Ideology and Meaning in Advertising. Londres: Marion Boyars.

Wlassikoff, M. (2008). Mai 68 L'Affiche en heritage. Paris: Editions Alternatives. 


\section{Anexo I}

\section{Parrilla de análisis de carteles sociales}

\begin{tabular}{|c|c|c|c|c|}
\hline \multirow{2}{*}{$\begin{array}{l}\text { Categorías } \\
\text { Códigos estéticos }\end{array}$} & \multicolumn{4}{|l|}{ Carteles } \\
\hline & Cobre Chileno & $\begin{array}{l}\text { Venceremos la } \\
\text { desnutrición }\end{array}$ & $\begin{array}{l}\text { Darle Duro a la } \\
\text { producción }\end{array}$ & $\begin{array}{l}\text { Ud. es } \\
\text { responsable salud }\end{array}$ \\
\hline \multicolumn{5}{|l|}{ Fotografía } \\
\hline Ilustración & $\mathrm{X}$ & $\mathrm{X}$ & $\mathrm{X}$ & $\mathrm{X}$ \\
\hline \multicolumn{5}{|l|}{ Fotografía intervenida } \\
\hline \multicolumn{5}{|l|}{$\begin{array}{l}\text { Descripción } \\
\text { cromática }\end{array}$} \\
\hline 4 colores & $\mathrm{X}$ & $\mathrm{X}$ & $\mathrm{X}$ & $\mathrm{X}$ \\
\hline \multicolumn{5}{|l|}{3 colores } \\
\hline \multicolumn{5}{|l|}{2 colores } \\
\hline \multicolumn{5}{|l|}{1 color } \\
\hline \multicolumn{5}{|l|}{$\begin{array}{l}\text { Presencia de } \\
\text { elementos simbólicos }\end{array}$} \\
\hline $\mathrm{Si}$ & $\mathrm{X}$ & $\mathrm{X}$ & $\mathrm{X}$ & $\mathrm{X}$ \\
\hline Cuáles & $\begin{array}{l}\text { Bandera, } \\
\text { elementos de } \\
\text { trabajo, lingotes } \\
\text { de cobre }\end{array}$ & $\begin{array}{l}\text { Bandera, vaso de } \\
\text { leche, pala }\end{array}$ & Martillo, casco & Mujer, cordillera \\
\hline \multicolumn{5}{|l|}{$\begin{array}{l}\text { Descripción } \\
\text { tipográfica }\end{array}$} \\
\hline \multicolumn{5}{|l|}{$\begin{array}{l}\text { Presencia de tipologías } \\
\text { gestuales }\end{array}$} \\
\hline Título & $\mathrm{X}$ & $\mathrm{X}$ & $\mathrm{X}$ & $\mathrm{X}$ \\
\hline Bajada de texto & $\mathrm{X}$ & $\mathrm{X}$ & $\mathrm{X}$ & $\mathrm{X}$ \\
\hline Ubicación de logotipo & & $\begin{array}{l}\text { Extremo superior } \\
\text { Izquierdo }\end{array}$ & & $\begin{array}{l}\text { Extremo superior } \\
\text { centrado }\end{array}$ \\
\hline \multicolumn{5}{|l|}{ Composición } \\
\hline Predominancia imagen & $\mathrm{X}$ & $\mathrm{X}$ & $\mathrm{X}$ & $\mathrm{X}$ \\
\hline \multicolumn{5}{|l|}{ Predominancia texto } \\
\hline $\begin{array}{l}\text { Identificación de } \\
\text { referentes estéticos }\end{array}$ & Arte Pop & $\begin{array}{l}\text { Pedro Lobos/ } \\
\text { muralismo }\end{array}$ & Arte Pop & $\begin{array}{l}\text { Pedro Lobos/ } \\
\text { Muralismo }\end{array}$ \\
\hline
\end{tabular}




\begin{tabular}{|c|c|c|c|c|}
\hline \multicolumn{5}{|l|}{ Mensajes } \\
\hline Texto principal & Cobre Chileno & $\begin{array}{l}\text { Venceremos la } \\
\text { desnutrición }\end{array}$ & $\begin{array}{l}\text { Darle Duro a la } \\
\text { producción }\end{array}$ & $\begin{array}{l}\text { Ud. también } \\
\text { puede ser } \\
\text { responsable salud }\end{array}$ \\
\hline Textos de apoyo & $\begin{array}{c}\text { Tú eres la } \\
\text { patria, pampa } \\
\text { y pueblo... } \\
\text { (Neruda) }\end{array}$ & $\begin{array}{c}\text { Con el pueblo y } \\
\text { el plan nacional } \\
\text { de leche }\end{array}$ & $\begin{array}{c}\text { En: fábricas, } \\
\text { minas y } \\
\text { campo. Trabajo } \\
\text { voluntario verano } \\
72\end{array}$ & $\begin{array}{l}\text { Inscríbase en el } \\
\text { consultorio de su } \\
\text { sector. Sus hijos y } \\
\text { los vecinos se lo } \\
\text { agradecerán }\end{array}$ \\
\hline Personajes/estereotipos & $\begin{array}{l}\text { Trabajadores, } \\
\text { diversidad } \\
\text { étnica, niños, } \\
\text { oficios, } \\
\text { profesionales }\end{array}$ & $\begin{array}{c}\text { Mujer } \\
\text { trabajadora, } \\
\text { mujer madre, } \\
\text { niños, } \\
\text { trabajadores }\end{array}$ & Obrero & $\begin{array}{l}\text { Mujer, imagen } \\
\text { cordillera }\end{array}$ \\
\hline $\begin{array}{l}\text { Identificación de } \\
\text { promesa base }\end{array}$ & $\begin{array}{l}\text { Cobre como } \\
\text { sustento de los } \\
\text { chilenos }\end{array}$ & $\begin{array}{c}\text { Vencer la } \\
\text { desnutrición }\end{array}$ & $\begin{array}{l}\text { La producción } \\
\text { como motor de } \\
\text { cambio social }\end{array}$ & $\begin{array}{l}\text { La salud como } \\
\text { responsabilidad } \\
\text { social }\end{array}$ \\
\hline \multicolumn{5}{|l|}{ Aspectos relacionales } \\
\hline $\begin{array}{l}\text { Relación mensaje- } \\
\text { receptor }\end{array}$ & $\begin{array}{l}\text { Testimoniar } \\
\text { la diversidad } \\
\text { de Chile } \\
\text { sustentada por } \\
\text { una riqueza } \\
\text { común }\end{array}$ & $\begin{array}{c}\text { Invitación a } \\
\text { unirse en una } \\
\text { tarea común: } \\
\text { Derrotar la } \\
\text { desnutrición vía } \\
\text { el consumo de } \\
\text { leche }\end{array}$ & $\begin{array}{l}\text { Invitación a la } \\
\text { participación } \\
\text { en actos } \\
\text { productivos } \\
\text { "trabajos de } \\
\text { verano" como } \\
\text { motor de cambio }\end{array}$ & $\begin{array}{l}\text { Apelativo al } \\
\text { individuo en } \\
\text { el logro de } \\
\text { mejoras en salud } \\
\text { comunitaria }\end{array}$ \\
\hline Imaginario referencial & $\begin{array}{l}\text { Cobre como } \\
\text { sustento del } \\
\text { pueblo diverso }\end{array}$ & $\begin{array}{l}\text { El pueblo en } \\
\text { su diversidad } \\
\text { con un mismo } \\
\text { objetivo: Vencer } \\
\text { la desnutrición }\end{array}$ & $\begin{array}{l}\text { Producir cambio } \\
\text { en función } \\
\text { del hacer e } \\
\text { involucramiento } \\
\text { individual }\end{array}$ & $\begin{array}{l}\text { La } \\
\text { responsabilidad } \\
\text { del individuo } \\
\text { en el cambio } \\
\text { positivo a nivel } \\
\text { social }\end{array}$ \\
\hline
\end{tabular}

